\title{
Prevalence of self-medication with antibiotics and its related factors among Chinese residents: a cross-sectional study
}

\author{
Xiaoxv Yin ${ }^{1 \dagger}$, Ketao $\mathrm{Mu}^{2+}$, Heping Yang ${ }^{3}$, Jing Wang ${ }^{1}$, Zhenyuan Chen ${ }^{1}$, Nan Jiang ${ }^{1}$, Fengjie Yang ${ }^{4}$, \\ Guopeng Zhang ${ }^{5^{*}}$ and Jianxiong $\mathrm{Wu}^{1^{*}}$
}

\begin{abstract}
Background: Self-medication is one of the most common forms of inappropriate use of antibiotics. This study aimed to assess the prevalence of self-medication with antibiotics (SMA) in China and evaluate the related factors.

Methods: A cross-sectional survey was conducted in Wuhan, Hubei, China from July 1, 2019 to July 31, 2019. Participants were recruited in public places to answer a structured questionnaire. The information of participants' social demographic characteristics, antibiotic knowledge and health beliefs were collected. Binary Logistics regression analysis was used to examine the associated factors of SMA.
\end{abstract}

Results: Of the 3206 participants, 10.32\% reported SMA in the past 6 months. Participants who with middle or high perceived barriers to seek health care services showed a higher likelihood of SMA $(P<0.05)$. Participants who with middle or high perceived threats of self-medication, and who with middle or high self-efficacy to overcome obstacles showed a lower likelihood of SMA $(P<0.05)$.

Conclusions: Compared with developed countries, the prevalence of SMA in China is still higher. Measures to conduct public health education and improve the accessibility of health services are crucial to decrease the overall self-medication rate in China.

Keywords: Antimicrobial stewardship, Antibiotic knowledge, China, Health belief model, Self-medication

\section{Introduction}

Under the combined action of biological and social factors, antimicrobial resistance (AMR) has become a serious threat to global public health $[1,2]$. AMR may lead

\footnotetext{
*Correspondence: zhgp81@163.com; wuqiyun1995@163.com

${ }^{+}$Xiaoxv Yin and Ketao Mu have contributed equally to this work.

1 Department of Social Medicine and Health Management, School of Public Health, Tongji Medical College, Huazhong University of Science and Technology, Wuhan 430030, Hubei, People's Republic of China ${ }^{5}$ Department of Nuclear Medicine, Tongji Hospital, Tongji Medical College, Huazhong University of Science and Technology, Wuhan, People's Republic of China

Full list of author information is available at the end of the article
}

to more than 100 trillion dollars in economic losses by 2050 [3]. Self-medication is one of the most prevalent form of inappropriate use of antibiotics, which is based on the self-judgment of patients but lack the professional diagnosis of doctors. Such irrational behaviour may lead to negative results, such as increased risk of AMR, failure of treatments and death of the patients [4].

The global self-medication with antibiotics (SMA) reaches alarmingly high rates, especially in low-and middle-income countries [5]. A study in Tanzania showed that $58.0 \%$ of the respondents admitted to SMA (SMA) [6]. Another Serbian study found that $27.17 \%$ of the original author(s) and the source, provide a link to the Creative Commons licence, and indicate if changes were made. The images or other third party material in this article are included in the article's Creative Commons licence, unless indicated otherwise in a credit line to the material. If material is not included in the article's Creative Commons licence and your intended use is not permitted by statutory regulation or exceeds the permitted use, you will need to obtain permission directly from the copyright holder. To view a copy of this licence, visit http://creativecommons.org/licenses/by/4.0/. The Creative Commons Public Domain Dedication waiver (http://creativeco mmons.org/publicdomain/zero/1.0/) applies to the data made available in this article, unless otherwise stated in a credit line to the data. 
households used antibiotics without prescriptions [7]. The related factors of SMA can be divided into external factors and internal factors. The sales of antibiotics without prescriptions may be an important external factor [8], which is intensely shared in low- and middle-income countries. Although most countries had issued legislations to against these practices, they had not been effectively implemented $[9,10]$. In terms of internal factors, previous studies found that age, income, education level and antibiotic knowledge were significantly correlated with self-medication [11-13].

The prevalence of SMA in China is also relatively high [14]. China's State Food and Drug Administration conducted a survey of 7915 residents, among whom $23.9 \%$ indicated that they would take antibiotics by themselves instead of seeing a doctor when they have a cold [15]. Another study conducted in rural areas of China found that $46.3 \%$ of villagers had experienced SMA [16]. A large number of studies have confirmed that the availability of over-the-counter antibiotics in China is very high $[15,17]$. Most Chinese residents still have easy access to non-prescription antibiotics, which may exacerbate SMA. However, there is little research on internal factors in China. Most of the relevant studies mainly focused on college students, teenagers or children $[18,19]$, but rarely involved the whole population. In addition, previous studies mainly focused on the relationship between demographic characteristics, antibiotic knowledge and SMA, while ignoring the role of health beliefs. Health beliefs may have a more direct impact on behaviours, which have been widely concerned in studies on health behaviours such as breast cancer screening and hypertension self-management $[20,21]$.

Thus, the aims of this study were to assess the prevalence of SMA among Chinese residents and identify the associated factors.

\section{Methods}

\section{Setting and participants}

A cross-sectional study was conducted in Wuhan, Hubei, China, from 1 July, 2019 to 31 July, 2019. Trained investigators recruited respondents in public places such as bus stops and parks by convenient sampling method. The inclusion criteria of the subjects were: (1) adults aged 18 and older; (2) those who were able to read and write Chinese. During the data collection period, a total of 4832 questionnaires were distributed, and 3420 respondents completed the questionnaire, with a response rate of 70.78\%. Among them, 129 questionnaires were deemed invalid because more than $25 \%$ of the items were missing, and 85 questionnaires were excluded because the respondents were younger than 18 years old. Finally, 3206 qualified questionnaires were included in the analysis.

\section{Measurement}

The main outcome of this study was the prevalence of SMA, measured by asking "Did you use antibiotics without seeing a doctor in the past 6 months?" In order to identify the relevant factors of SMA, this study also collected the social demographic characteristics (gender, age, residence, educational level, self-perceived economic status, self-perceived health status), antibiotic knowledge, health beliefs of SMA.

A self-designed scale was used to measure the health beliefs of SMA. The scale is based on health belief model, including four dimensions: perceived threats, perceived benefits, perceived barriers and self-efficacy. Perceived threats refer to the degree of perceived harm caused by SMA. Perceived benefits refer to the perceived benefit of taking antibiotics under the guidance of a doctor. Perceived barriers refer to the perception of difficulty in taking antibiotics under the guidance of a doctor. Selfefficacy is the determination to overcome obstacles to seeking medical care and to take antibiotics under the guidance of a doctor. The overall Cronbach's $\alpha$ coefficient of the scale was 0.80 . The Cronbach's $\alpha$ coefficients of each dimension are as follows: perceived threats (0.89), perceived benefits $(0.94)$, perceived barriers $(0.80)$, selfefficacy (0.84). There are 4 items of perceived threats and 5 items of perceived benefits, perceived barriers and self-efficacy respectively. Each item used Likert's 5-point scoring method, from "totally disagree" to "totally agree", scoring 1-5 points respectively. According to the lower quartile and the upper quartile of the score, the participants' health beliefs were divided into three groups: high, middle and low.

The participants' antibiotic knowledge was measured by an Antibiotic Knowledge Scale developed by our group. The scale included 10 items with the Cronbach's $\alpha$ coefficient of 0.72 . Each knowledge item was given a score of one point if the participant answered correctly, and a score of zero if the answer was wrong or "I don't know". So, the total score of this scale ranged from 0 to 10. The higher the score, the better the antibiotic knowledge of participants. According to the lower quartile and the upper quartile of the score, the participants' antibiotic knowledge level was divided into three groups: high, middle and low.

\section{Statistical analysis}

We used SPSS version 22.0 for Windows (IBM Corp., Armonk, NY, USA) for all analysis (see Additional file 1: Appendix S1 for the statistical analysis process). Descriptive statistical methods such as frequency, percentage, mean and standard deviation (SD) were used to present demographic characteristics, antibiotic knowledge, 
health belief and other variables. Pearson Chi-Square test was used to compare the prevalence of self-medication among participants with different characteristics. Binary Logistics regression model was used to explore the related factors of SMA. Adjusted odd ratios (ORs) and $95 \%$ confidence intervals (CIs) for each variable were given. Possible multicollinearity of variables in the model was assessed by calculating variance inflation factors (VIFs) and pairwise correlation coefficient (see Additional file 2: Appendix S2 for the multicollinearity text). Differences were tested by using two-tailed tests. If $P<0.05$, the result was considered statistically significant.

\section{Results}

\section{General characteristics and SMA of participants}

Table 1 shows the demographic characteristics differences between groups defined by SMA. In the past
6 months, $10.32 \%$ of participants $(331 / 3206)$ reported SMA. The majority of the participants were women (66.50\%), with an average age of $33.41 \pm 10.83$ years old. Nearly $80 \%$ lived in cities, and more than half of the participants had college degrees or above. In addition, $73.74 \%$ rated their economic status as average, and $52.74 \%$ rated their health status as good. Furthermore, $48.60 \%$ reported that they stored antibiotics at home for use.

With the self-medication as the dependent variable, Pearson chi-square test was used to analyse the statistical differences. The results showed that there were significant differences in self-medication among participants of different ages, residences, educational level, self-perceived health status and self-perceived economic status.

Table 1 Participants' characteristics and associations with SMA N (\%)

\begin{tabular}{|c|c|c|c|c|c|}
\hline \multirow[t]{2}{*}{ Variables } & \multirow[t]{2}{*}{ Number } & \multicolumn{2}{|c|}{ Antibiotics self-medication } & \multirow[t]{2}{*}{$x^{2}$} & \multirow[t]{2}{*}{$P$} \\
\hline & & Yes & No & & \\
\hline Gender & & & & 3.013 & 0.083 \\
\hline Male & $1074(33.50)$ & $125(11.64)$ & 949 (88.36) & & \\
\hline Female & $2132(66.50)$ & $206(9.66)$ & $1926(90.34)$ & & \\
\hline Age & & & & 10.023 & 0.018 \\
\hline$\leq 24$ & $759(23.67)$ & $64(8.43)$ & 695 (91.57) & & \\
\hline $25-44$ & $1859(57.99)$ & $188(10.11)$ & $1671(89.89)$ & & \\
\hline $45-59$ & $528(16.47)$ & $73(13.83)$ & $455(86.17)$ & & \\
\hline$\geq 60$ & $60(1.87)$ & $6(10.00)$ & $54(90.00)$ & & \\
\hline Location & & & & 5.497 & 0.019 \\
\hline Urban & $2470(77.04)$ & $272(11.01)$ & $2198(88.99)$ & & \\
\hline Rural & $736(22.96)$ & $59(8.02)$ & $677(91.98)$ & & \\
\hline Education level & & & & 7.982 & 0.046 \\
\hline Junior high school and below & $470(14.66)$ & $40(8.51)$ & $430(91.49)$ & & \\
\hline High school & $703(21.93)$ & $76(10.81)$ & $627(89.19)$ & & \\
\hline Undergraduate & $1475(46.01)$ & $141(9.56)$ & $1334(90.44)$ & & \\
\hline Postgraduate and above & $558(17.40)$ & $74(13.26)$ & $484(86.74)$ & & \\
\hline Self-perceived health status & & & & 8.480 & 0.014 \\
\hline Good & $1691(52.74)$ & $155(9.17)$ & $1536(90.83)$ & & \\
\hline Average & $1334(41.61)$ & $148(11.09)$ & $1186(88.91)$ & & \\
\hline Poor & $181(5.65)$ & $28(15.47)$ & $153(84.53)$ & & \\
\hline Self-perceived economic status & & & & 10.800 & 0.005 \\
\hline Good & $452(14.10)$ & $66(14.60)$ & $386(85.40)$ & & \\
\hline Average & $2364(73.74)$ & $231(9.77)$ & $2133(90.23)$ & & \\
\hline Poor & $390(12.16)$ & $34(8.72)$ & $356(91.28)$ & & \\
\hline \multicolumn{6}{|l|}{ Reserve antibiotics at home } \\
\hline Hardly & $1228(38.30)$ & $187(15.23)$ & $1041(84.77)$ & 74.275 & 0.000 \\
\hline Occasionally & $330(10.29)$ & $48(14.55)$ & $282(85.45)$ & & \\
\hline Always & $1648(51.40)$ & $96(5.83)$ & $1552(94.17)$ & & \\
\hline Total & $3206(100)$ & $331(10.32)$ & $2875(89.68)$ & & \\
\hline
\end{tabular}




\section{Antibiotic health beliefs and antibiotic knowledge of participants}

Table 2 presents the participants' health beliefs and knowledge about antibiotics. In terms of health beliefs, the average scores of perceived threats, perceived benefits, perceived barriers and self-efficacy were $14.46 \pm 3.51$, $20.92 \pm 4.14,13.80 \pm 4.31$ and $18.17 \pm 3.93$, respectively. The percentages of participants with high perception of health beliefs in all dimensions were as follows: perceived threats $(19.68 \%)$, perceived benefits $(30.75 \%)$, perceived barriers $(20.02 \%)$, and self-efficacy $(23.42 \%)$. The average score of antibiotic knowledge of the participants was $6.86 \pm 2.27$. According to the quartile, the proportion of participants with higher antibiotic knowledge level is 12.04\%.

Univariate analysis showed that there were significant differences in the prevalence of self-medication among participants with different level of perceived threats, perceived barriers and self-efficacy.

\section{The factors associated with SMA}

Before the multivariate analysis, we performed multicollinearity test on the he independent variables. The VIFs of independent variables were less than 10 and pairwise correlation coefficients were less than 0.4, indicating multicollinearity was not observed in the model.
Table 3 presents the multivariate analysis of SMA. Participants who rated themselves as in good economy status $(\mathrm{OR}=1.81,95 \% \mathrm{CI} 1.10-2.96)$, always $(\mathrm{OR}=2.62$; $95 \%$ CI $2.01-3.43)$ and occasionally $(\mathrm{OR}=2.34 ; 95 \% \mathrm{CI}$ 1.60-3.41) stored antibiotics at home, with middle $(\mathrm{OR}=1.77 ; 95 \% \mathrm{CI} 1.11-2.83)$ or high $(\mathrm{OR}=2.59 ; 95 \% \mathrm{CI}$ 1.56-4.29) perceived barriers showed a higher likelihood of SMA. Participants who rated themselves as in good health status $(\mathrm{OR}=0.55$; 95\% CI $0.35-0.88)$, with middle $(\mathrm{OR}=0.69 ; 95 \% \mathrm{CI} 0.51-0.93)$ or high $(\mathrm{OR}=0.41 ; 95 \% \mathrm{CI}$ $0.26-0.66)$ perceived threats, and with middle $(\mathrm{OR}=0.68$; $95 \%$ CI $0.51-0.92)$ or high $(\mathrm{OR}=0.47$; 95\%CI $0.31-0.73)$ self-efficacy showed a lower likelihood of SMA.

\section{Discussion}

This study found that $10.32 \%$ of the participants had self-medicated themselves with antibiotics in the past 6 months. The ratio is lower than that in most developing countries, such as Pakistan (45\%) [22] and Ghana (40\%) [23], but higher than that in some developed countries, such as the United Kingdom (5\%) [24]. It may be attributable to the differences in socio-economic and the sample population. Additionally, nearly half of the participants in this study stored antibiotics at home, which is considered as the main source of antibiotics for self-use [25, 26]. The results of multivariate analysis also confirmed that

Table 2 Participants' antibiotic knowledge level and health beliefs N (\%)

\begin{tabular}{|c|c|c|c|c|c|}
\hline \multirow[t]{2}{*}{ Variables } & \multirow[t]{2}{*}{ Number } & \multicolumn{2}{|c|}{ Antibiotics self-medication } & \multirow[t]{2}{*}{$x^{2}$} & \multirow[t]{2}{*}{$P$} \\
\hline & & Yes & No & & \\
\hline Perceived threats & & & & 27.936 & $<0.001$ \\
\hline High & $631(19.68)$ & $34(5.39)$ & $597(94.61)$ & & \\
\hline Middle & $2076(64.75)$ & $223(10.74)$ & $1853(89.26)$ & & \\
\hline Low & $499(15.56)$ & $74(14.83)$ & $425(85.17)$ & & \\
\hline Perceived benefits & & & & 3.343 & 0.188 \\
\hline High & $986(30.75)$ & $88(8.92)$ & $898(91.08)$ & & \\
\hline Middle & $1488(46.32)$ & 159 (10.69) & $1329(89.31)$ & & \\
\hline Low & $732(22.83)$ & $84(11.48)$ & $648(88.52)$ & & \\
\hline Perceived barriers & & & & 37.471 & $<0.001$ \\
\hline High & $642(20.02)$ & $99(15.42)$ & $543(84.58)$ & & \\
\hline Middle & $2059(64.22)$ & $210(10.20)$ & $1849(89.80)$ & & \\
\hline Low & $505(15.75)$ & $22(4.36)$ & $483(95.64)$ & & \\
\hline Self-efficacy & & & & 31.187 & $<0.001$ \\
\hline High & $751(23.42)$ & $43(5.72)$ & $708(94.27)$ & & \\
\hline Middle & $1937(60.42)$ & 209 (10.79) & 1728 (89.21) & & \\
\hline Low & $518(16.16)$ & $79(15.25)$ & $439(84.75)$ & & \\
\hline Antibiotic knowledge level & & & & 0.296 & 0.863 \\
\hline High & $386(12.04)$ & $41(10.62)$ & $345(89.38)$ & & \\
\hline Middle & $2306(71.93)$ & $234(10.15)$ & $2072(89.85)$ & & \\
\hline Low & $514(16.03)$ & $56(10.89)$ & $458(89.10)$ & & \\
\hline
\end{tabular}


Table 3 Logistic regression analysis results of SMA

\begin{tabular}{|c|c|c|}
\hline Variables & Adjusted OR $(95 \% \mathrm{Cl})$ & $P$ \\
\hline \multicolumn{3}{|l|}{ Gender (Ref = Female) } \\
\hline Male & $1.13(0.88-1.45)$ & 0.334 \\
\hline \multicolumn{3}{|l|}{ Age $($ ref $\leq 24)$} \\
\hline $25-44$ & $1.21(0.88-1.66)$ & 0.251 \\
\hline $45-59$ & $1.41(0.96-2.08)$ & 0.084 \\
\hline$\geq 60$ & $1.06(0.42-2.69)$ & 0.906 \\
\hline \multicolumn{3}{|l|}{ Location (ref =Village) } \\
\hline Urban & $1.24(0.90-1.71)$ & 0.196 \\
\hline \multicolumn{3}{|c|}{ Education level (ref = Junior high school and below) } \\
\hline High school & $1.28(0.84-1.95)$ & 0.257 \\
\hline Undergraduate & $1.16(0.77-1.73)$ & 0.484 \\
\hline Postgraduate and above & $1.49(0.95-2.33)$ & 0.086 \\
\hline \multicolumn{3}{|c|}{ Self-perceived health status (ref = Poor) } \\
\hline Average & $0.66(0.41-1.07)$ & 0.084 \\
\hline Good & $0.55(0.35-0.88)$ & 0.013 \\
\hline \multicolumn{3}{|c|}{ Self-perceived economic status ( $r e f=$ Poor) } \\
\hline Average & $1.22(0.81-1.84)$ & 0.341 \\
\hline Good & $1.81(1.10-2.96)$ & 0.019 \\
\hline \multicolumn{3}{|c|}{ Reserve antibiotics at home (ref $=$ Hardly) } \\
\hline Occasionally & $2.34(1.60-3.41)$ & $<0.001$ \\
\hline Always & $2.62(2.01-3.43)$ & $<0.001$ \\
\hline \multicolumn{3}{|c|}{ Antibiotic knowledge level (ref=Low) } \\
\hline Middle & $0.92(0.66-1.28)$ & 0.621 \\
\hline High & $0.89(0.55-1.44)$ & 0.637 \\
\hline \multicolumn{3}{|l|}{ Perceived threats (ref $=$ Low) } \\
\hline Middle & $0.69(0.51-0.93)$ & 0.015 \\
\hline High & $0.42(0.26-0.66)$ & $<0.001$ \\
\hline \multicolumn{3}{|l|}{ Perceived benefits (ref $=$ Low) } \\
\hline Middle & $1.04(0.76-1.41)$ & 0.813 \\
\hline High & $1.09(0.76-1.58)$ & 0.629 \\
\hline \multicolumn{3}{|l|}{ Perceived barriers (ref = Low) } \\
\hline Middle & $1.77(1.11-2.83)$ & 0.017 \\
\hline High & $2.59(1.56-4.29)$ & $<0.001^{* * *}$ \\
\hline \multicolumn{3}{|l|}{ Self-efficacy (ref = Low) } \\
\hline Middle & $0.68(0.51-0.92)$ & 0.012 \\
\hline High & $0.47(0.31-0.73)$ & 0.001 \\
\hline
\end{tabular}

participants who stored antibiotics at homes were more likely to self-medicate themselves.

Participants in this study still had some misconceptions regarding antibiotics. For instance, $72.4 \%$ believed that antibiotics can cure viral infections. Knowledge is a prerequisite for behaviour change, providing individuals with basic information for health decision-making $[27,28]$. Nevertheless, no significant association was found between antibiotic knowledge and SMA in current study. Previous studies also indicated that the relationship between the improvement of knowledge and the rational use of antibiotics was not simple, and merely increasing public knowledge about antibiotics may even be counterproductive [24, 29]. Health decision-making is a complex process in which individuals weigh benefits and risks [30]. Providing accurate knowledge is not enough. The changes in individual behaviour were more driven by the perception of possible adverse consequences [31, 32]. Therefore, in addition to antibiotic knowledge, we also focused on the role of health beliefs in the behavioral process. 
Our study revealed that health beliefs were closely related to SMA. Individuals' perception of risks can avoid the occurrence of improper behaviours or reduce their severity [32]. Participants with high perceived threats were less likely to report SMA. When interventions successfully change an individual's risk awareness, they usually promote the transformation of improper behaviours [33]. It is necessary to carry out national antibiotic intervention programs on the irrational use of antibiotics to help residents realize the harmfulness of SMA. Participants with high perceived barriers were more likely to report self-medication. On the contrary, the higher the self-efficacy of overcoming the obstacle, the less likely they were to report self-medication. A previous study have attributed the high prevalence of self-medication to poor access to health care [34]. In addition to carrying out extensive health education, the government should also improve the accessibility of health care services to remove barriers of behavioral change.

There was a correlation between socio-demographic variables and self-medication. However, due to the different research sites and sample groups, the existing evidence is inconsistent. There is a positive correlation between economic status and self-medication in this study, which is in accord with the findings in Jordan [11], but contrary to that of Ethiopia [12]. Participants who rated themselves as in good health were less likely to self-medicate, which was consistent with the results of an Italian study [35]. Unlike previous studies, this study found no significant association between education level and self-medication. The national antibiotic intervention program should define the target population to achieve a better intervention effect.

Based on the health belief model, our study analysed the relationship between health beliefs and SMA, which was not found in previous studies. However, this study also has some limitations. First of all, there were inherent defects of a cross-sectional study, such as recall bias and difficulty in inference of causal conclusions. It is essential to further test the conclusions of this study by prospective research. Secondly, due to the lack of a scale measuring health belief in SMA, we developed a relevant scale to measure this concept. The reliability and validity of the scale need to be further tested.

\section{Conclusions}

Compared with developed countries, the prevalence of SMA in China is still higher. Health beliefs were significantly associated with SMA. The national antibiotic intervention program should help residents understand the harm of self-medication while publicizing antibiotic knowledge. In the meanwhile, the Chinese government should improve the accessibility of health services to reduce the external obstacles to behavior change.

Abbreviations

AMR: antimicrobial resistance; SMA: self-medication with antibiotics.

\section{Supplementary Information}

The online version contains supplementary material available at https://doi. org/10.1186/s13756-021-00954-3.

Additional file 1: Appendix S1 for the statistical analysis process.

Additional file 2: Appendix S2 for the multicollinearity text.

\section{Acknowledgements}

None

\section{Authors' contributions}

JW and FY contributed to the conception and design of the study. XY and KM conducted the data analysis and drafted the manuscript. $H Y$ and $X Y$ contributed to the acquisition of data. GZ JW, ZC and NJ critically revised the manuscript. All authors reviewed the manuscript and approved it to be submitted.

\section{Funding}

This work was supported by the National Natural Science Foundation of China (No.71874060).

\section{Availability of data and materials}

The datasets in the present study are accessible from the corresponding author on reasonable request.

\section{Ethics statement}

This study was approved by the Medical Ethics Committee of Tongji Medical College, Huazhong University of Science and Technology. All respondents were aware of the purpose of this study and consented to participate in the survey.

\section{Consent for publication}

Not applicable.

\section{Competing interests}

The authors declare that they have no competing interests.

\section{Author details}

${ }^{1}$ Department of Social Medicine and Health Management, School of Public Health, Tongji Medical College, Huazhong University of Science and Technology, Wuhan 430030, Hubei, People's Republic of China. ${ }^{2}$ Department of Radiology, Tongji Hospital, Tongji Medical College, Huazhong University of Science and Technology, Jie Fang Avenue 1095, Wuhan 430030, People's Republic of China. ${ }^{3}$ Wuchang University of Technology, Wuhan, Hubei, People's Republic of China. ${ }^{4}$ Department of Pediatrics, Tongji Hospital, Tongji Medical College, Huazhong University of Science and Technology, Wuhan 430030, Hubei,

People's Republic of China. ${ }^{5}$ Department of Nuclear Medicine, Tongji Hospital, Tongji Medical College, Huazhong University of Science and Technology, Wuhan, People's Republic of China.

Received: 31 January 2021 Accepted: 17 May 2021

Published online: 05 June 2021

\section{References}

1. Strong stewardship to fight antimicrobial resistance. Lancet. 2016;387(10029):1694.

2. Taubes G. The bacteria fight back. Science. 2008;321(5887):356-61.

3. Piddock LJV. Reflecting on the final report of the $\mathrm{O}^{\prime}$ Neill review on antimicrobial resistance. Lancet Infect Dis. 2016;16(7):767-8. 
4. Alhomoud F, Aljamea Z, Basalelah L. "Antibiotics kill things very quickly"consumers' perspectives on non-prescribed antibiotic use in Saudi Arabia. BMC Public Health. 2018;18(1):1177.

5. Ocan M, Obuku EA, Bwanga F, et al. Household antimicrobial self-medication: a systematic review and meta-analysis of the burden, risk factors and outcomes in developing countries. BMC Public Health. 2015;15:742.

6. Horumpende PG, Said SH, Mazuguni FS, et al. Prevalence, determinants and knowledge of antibacterial self-medication: a cross sectional study in North-eastern Tanzania. PLoS ONE. 2018;13(10):e0206623.

7. Tomas A, Paut Kusturica M, Tomić Z, et al. Self-medication with antibiotics in Serbian households: A case for action? Int J Clin Pharm. 2017;39(3):507-13.

8. Bin Nafisah S, Bin Nafesa S, Alamery AH, et al. Over-the-counter antibiotics in Saudi Arabia, an urgent call for policy makers. J Infect Public Health. 2017;10(5):522-6.

9. Gelband H, Miller-Petrie M, Pant S, et al. The state of the world's antibiotics 2015. Wound Heal South Afr. 2015;8(2):30-4.

10. Van Boeckel TP, Gandra S, Ashok A, et al. Global antibiotic consumption 2000 to 2010: an analysis of national pharmaceutical sales data. Lancet Infect Dis. 2014:14(8):742-50.

11. Al-Azzam SI, Al-Husein BA, Alzoubi F, et al. Self-medication with antibiotics in Jordanian population. Int J Occup Med Environ Health. 2007;20(4):373-80.

12. Bogale AA, Amhare AF, Chang J, et al. Knowledge, attitude, and practice of self-medication with antibiotics among community residents in Addis Ababa, Ethiopia. Expert Rev Anti Infect Ther. 2019;17(6):459-66.

13. Grigoryan L, Haaijer-Ruskamp FM, Burgerhof JGM, et al. Self-medication with antimicrobial drugs in Europe. Emerg Infect Dis. 2006;12(3):452-9.

14. Wang $X M$, Zhou XD, Hesketh T. Massive misuse of antibiotics by university students in China: a cross-sectional survey. Lancet. 2016;388(Suppl 1):S94.

15. Fang Y. China should curb non-prescription use of antibiotics in the community. BMJ. 2014;348:g4233.

16. Cheng J, Coope C, Chai J, et al. Knowledge and behaviors in relation to antibiotic use among rural residents in Anhui, China. Pharmacoepidemiol Drug Saf. 2018;27(6):652-9.

17. Chang J, Xu S, Zhu S, et al. Assessment of non-prescription antibiotic dispensing at community pharmacies in China with simulated clients: a mixed cross-sectional and longitudinal study. Lancet Infect Dis. 2019;19(12):1345-54.

18. Peng D, Wang $X, X u Y$, et al. Antibiotic misuse among university students in developed and less developed regions of China: a cross-sectional survey. Glob Health Action. 2018;11(1):1496973.

19. Lv B, Zhou Z, Xu G, et al. Knowledge, attitudes and practices concerning self-medication with antibiotics among university students in western China. Trop Med Int Health. 2014;19(7):769-79.

20. Che Mohamed N, Moey SF, Lim BC. Validity and reliability of health belief model questionnaire for promoting breast self-examination and screening mammogram for early cancer detection. Asian Pac J Cancer Prev. 2019;20(9):2865-73.
21. Ma C. An investigation of factors influencing self-care behaviors in young and middle-aged adults with hypertension based on a health belief model. Heart Lung. 2018;47(2):136-41.

22. Gillani AH, Ji W, Hussain W, et al. Antibiotic self-medication among nonmedical university students in Punjab, Pakistan: a cross-sectional survey. Int J Environ Res Public Health. 2017;14(10):1152.

23. Ahiabu MA, Magnussen P, Bygbjerg IC, et al. Treatment practices of households and antibiotic dispensing in medicine outlets in developing countries: the case of Ghana. Res Soc Adm Pharm. 2018:14(12):1180-8.

24. McNulty CA, Boyle P, Nichols T, et al. Don't wear me out-the public's knowledge of and attitudes to antibiotic use. J Antimicrob Chemother. 2007;59(4):727-38.

25. Abduelkarem AR, Othman AM, Abuelkhair ZM, et al. Prevalence of selfmedication with antibiotics among residents in United Arab Emirates. Infect Drug Resist. 2019;12:3445-53.

26. Skliros E, Merkouris P, Papazafiropoulou A, et al. Self-medication with antibiotics in rural population in Greece: a cross-sectional multicenter study. BMC Fam Pract. 2010:11:58.

27. Stanton R, Scott D, Happell B. Low knowledge of physical health behaviours is associated with poor diet and chronic illness in adults. Aust J Prim Health. 2016;22(3):226-32.

28. Racey M, Machmueller D, Field D, et al. Perceptions and use of sources of health knowledge by young adolescents. Int J Adolesc Med Health. 2016. https://doi.org/10.1515/ijamh-2016-0002.

29. Cagri Buke A, Ermertcan S, Hosgor-Limoncu M, et al. Rational antibiotic use and academic staff. Int J Antimicrob Agents. 2003;21(1):63-6.

30. Stålsby Lundborg C, Tamhankar AJ. Understanding and changing human behaviour-antibiotic mainstreaming as an approach to facilitate modification of provider and consumer behaviour. Ups J Med Sci. 2014;119(2):125-33

31. Becker MH. The health belief model and sick role behavior. Health Educ Monogr. 1974;2(4):409-19.

32. Ferrer R, Klein WM. Risk perceptions and health behavior. Curr Opin Psychol. 2015;5:85-9.

33. Sheeran P, Harris PR, Epton T. Does heightening risk appraisals change people's intentions and behavior? A meta-analysis of experimental studies. Psychol Bull. 2014;140(2):511-43.

34. Ramay BM, Lambour P, Cerón A. Comparing antibiotic self-medication in two socio-economic groups in Guatemala City: a descriptive crosssectional study. BMC Pharmacol Toxicol. 2015;16:11.

35. Napolitano F, Izzo MT, Di Giuseppe G, et al. Public knowledge, attitudes, and experience regarding the use of antibiotics in Italy. PLOS ONE. 2013;8(12):e84177.

\section{Publisher's Note}

Springer Nature remains neutral with regard to jurisdictional claims in published maps and institutional affiliations.
Ready to submit your research? Choose BMC and benefit from:

- fast, convenient online submission

- thorough peer review by experienced researchers in your field

- rapid publication on acceptance

- support for research data, including large and complex data types

- gold Open Access which fosters wider collaboration and increased citations

- maximum visibility for your research: over $100 \mathrm{M}$ website views per year

At BMC, research is always in progress.

Learn more biomedcentral.com/submissions 